\title{
Identity and the Arts: Using Drama and Masks as a Pedagogical Tool to Support Identity Development in Adolescence
}

\author{
David Roy, James Ladwig \\ University of Newcastle (AUS), Callaghan, Australia \\ Email: david.roy@newcastle.edu.au
}

Received 24 March 2015; accepted 12 June 2015; published 18 June 2015

Copyright (C 2015 by authors and Scientific Research Publishing Inc.

This work is licensed under the Creative Commons Attribution International License (CC BY). http://creativecommons.org/licenses/by/4.0/

c) (i) Open Access

\begin{abstract}
Identity in adolescents is an ever-growing concern and pre-occupation within formal education, with a need to identify factors that can positively impact upon adolescent development. Identity and understanding of the human condition has been apparent from earliest records of Homo sapiens. One of the earliest recorded exploration and understanding of this is through ritual ceremony and the role that mask has played in allowing people to explore what it means to us through adopting the "other". It therefore stands to reason that if masks have and still do allow individuals to explore identity and place in life, there may be an impact upon adolescents who use masks within their formal drama education. This paper explores: The concepts of identity having a correspondence to mask usage; The potential for masks to support the individual to disassociate from the self; and the sense of being.. If we wish to support adolescent development and self awareness, at the core of drama curricula we need to re-position the usage of masks in the classroom beyond being tied to core historical academic knowledge but as a pedagogical methodology in its own right, we need to support adolescent exploration of identity.
\end{abstract}

\section{Keywords}

Drama, Secondary School Curriculum, Identity, Developmental Disabilities, Personal Development

\section{Introduction}

"The mask is powerful, dynamic, and iconographic. It can represent a fixed moment, a psychological motif or an emblematic emotional state." (Wainscott \& Fletcher, 2010: p 163)

Through the mask, the individual has the potential to challenge the understanding of whom they are through 
their body now being separated from the visual identifier of their face (Wilsher, 2007). This challenge can be personal or with the audience (Barba \& Savarese, 2006). The definitions of mask demonstrate this, from the Arabic maskhahra: to falsify or transform to the English form of mask to conceal (Nunley \& McCarthy, 1999). The human mind focuses clearly on the face of the individual, and thus through the concealment of this core identifier, the mask allows the individual to be separated from their "id" and their movements to be interpreted as separate to the individual (Ching \& Ching, 2006; Edson, 2005; Griffiths, 1998; Hamilton, 1997). Masks are synonymous with drama and theatre. Theatre, drama and drama education (as a curricular subject within schools) are each subtly different though not mutually exclusive. Drama education uses drama as the method to allow theatre as the art form to engage with.

"If Drama is about meaning, it is the art form of theatre which encompasses and contains that meaning. If theatre is about expression, then it is the dramatic exploration of the meaning which fuels that exploration" (Morgan \& Saxton, 1987: p. 1)

Yet, to fully understand the role that masks play in drama education we have to have an understanding of how they potentially impact upon individuals' identity and self-awareness development. Masks have played various roles in society from earliest times to the present (Wainscott \& Fletcher, 2010). These have included community ritual, performance and aesthetics. This has had an impact upon the understanding of who we are as a people, on our development of the idea of self. The key areas of masks to contextualize are not distinct but interact with each other (Figure 1).

The background for masks in context is based on the four primary areas and the research frameworks for this analysis of their role in educational practice stem from the following.

- Anthropology;

- Psychology;

- Theatre;

- Drama Education.

Theatrical practice is distinct from educational practice, though it informs the philosophical rationale of drama in education and the possible impacts and resonances. Part of the role that masks have been shown to develop is the physicality of a performer and their control. Through this knowledge, it is also therefore important to understand if the usage of masks has any impact, not only on the psychology of adolescents, but also upon developmental learning.

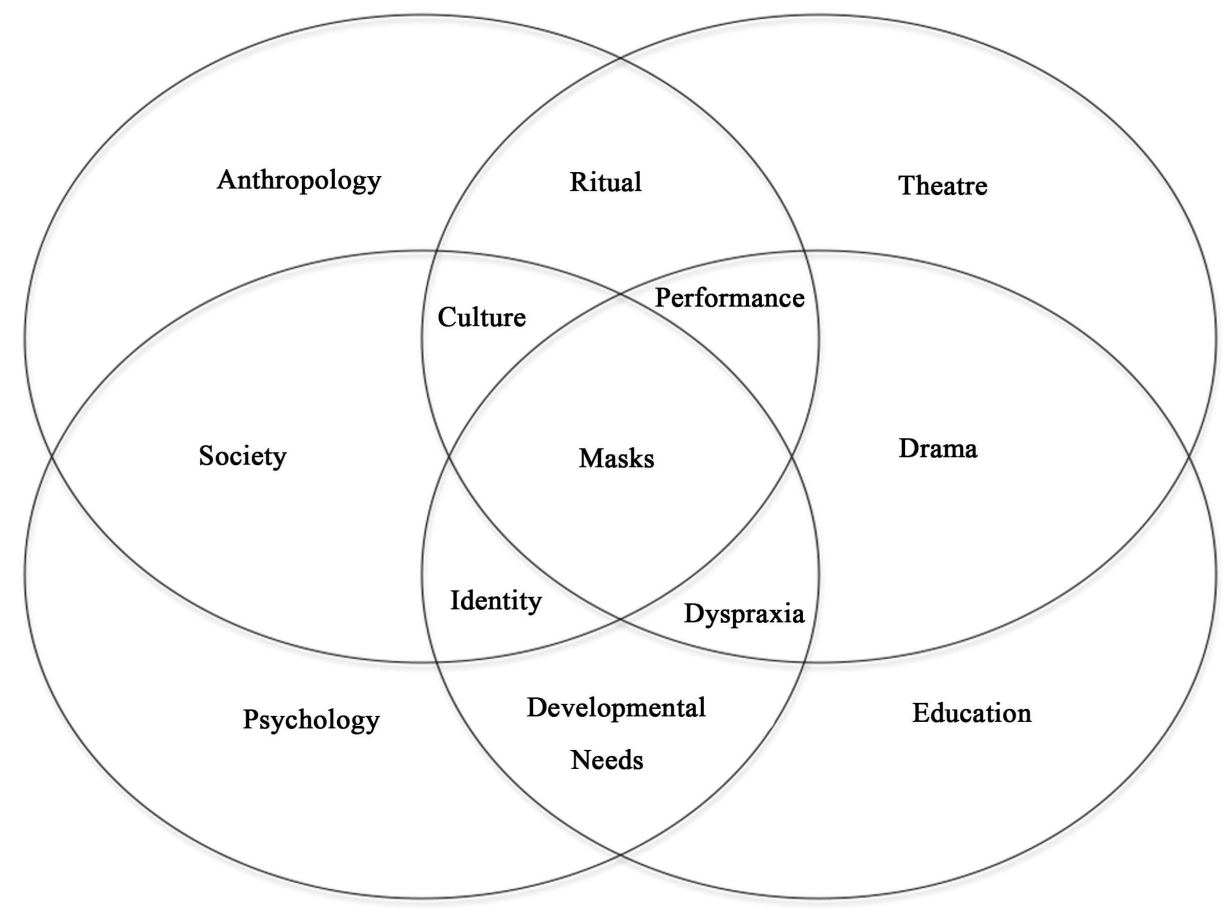

Figure 1. Interaction of mask knowledge. 


\section{Mask Anthropology}

Shaman undertook mask usage to allow them to represent and embody the spirit world such as represented on the rock art ay Trois Frères, France or Aunanrat, Tassil in Algeria during the Mesolithic period (Lévi-Strauss, 1982). What then is the effect this may have upon modern students? Throughout history the mask has allowed a freedom and license for individuals to adopt personae and roles other than their own (Edson, 2005; Mack, 1994; Nunley \& McCarthy, 1999). In the Masquerades of medieval times the individual was relaxed of responsibility and the moral certitude of the times, so that through the time period they could revel in the society's perceptions of immorality without fear of retribution (Twycross \& Carpenter, 2002).

"They serve to liberate the wearer from the inhibitions, laws and niceties of a seemingly well-ordered everyday life but are also a reminder that chaos and destruction and mutability are always with us.” (Foreman, 2000: p. 27-29)

There are few, if any societies in the world, which do not find references or images of masks and their application in the earliest historical records (Edson, 2005). The role and purpose of the mask has always been to transport and transform the user and the observer (Foreman, 2000). Masks have an audience, whether in entertainment or ritual and the difference between these two can cross boundaries. In both ritual and performance, the mask is as fascinating for the individuals who partake as they are actively engaged and yet able to glorify and observe the spectacle around them (Campbell, 1969).

The idea of the mask as a representation of identity and exploration is still a fluid one as found the modern celebrations of Halloween, Scotland; Day of the Dead, Mexico; Guy Fawkes, England; Venice Carnival, Italy; or indeed within media such as the graphic novel/film 'V for Vendetta' (Moore \& Lloyd, 1990). There is a freedom to masks that bridge societal needs within the context of liberation versus chaos as well as performance applications. As drama is often about the transformation of the individual into the "other", so as to explore aspects of the human condition in whatever form, masks must create an impact.

Nunley and McCarthy's overview of performance and anthropology is directly relevant to education. Through the use of masks within the classroom, this paper proposes that there is a potential to free students to explore their identities and establish their id in the adolescent year. This helps to fulfill one of the purposes of schooling on multiple levels. One is exploring curricular skill needs and the other is the wider "hidden curriculum" of creating individuals with skills to embrace society. It is not the purpose of this research to redefine the source neither of identity nor of offering an overarching theory to a definition of culture and place within this research. Claude Levi-Strauss asserts that it does not matter whether culture is integrated or merely a collage with no underlying pattern (Lévi-Strauss, 1982). Nor is it crucial to determine whether cognitive relativism is a cogent application to culture, despite the variance of languages in culture that therefore could be seen to undermine such an idea (Just \& Monaghan, 2000). Masks are one of the few objects that appear to transcend all of these theories. It is simply that masks have a role in all cultures.

There is no definitive time when masks can be seen to be first introduced, as they are ever present in visual records, but their purpose is and has always been to transport and transform the user and the observer (Foreman, 2000). Thus, masks have an audience, whether in entertainment or ritual. The difference between these two can cross boundaries. Ritual, similar to entertainment performance, is fascinating for the individuals who partake as they are actively engaged and yet able to glorify and observe the spectacle around them (Campbell, 1969).

Donald Pollock recognizes this wider purpose in the meaning of masks as an aspect of semiotic identity in society.

"Identity is displayed, revealed or hidden in any culture through conventional means, and that masks work by taking up these conventional means, iconically or indexically.” (Pollock, 1995: p. 582)

This is supported through the work of other anthropologists that masks have several functions such as representational, emotive indexical and disguise (Urban \& Hendriks, 1983). All these are observed in the multitude of modern usage of masks outside of the drama and theatre perspective, such as in modern religious festivals and events, children's play, religious attire and indeed in practical mask usage such as for health and medicine. In all these forms, their functions have a visual linguistic association that has the potential to impact how masks in the classroom are engaged (Pollock, 1995).

Masks have remained prevalent through human society as a form of celebration and religion. Drama and religion and celebration have link in that they all communicate important societal thoughts, whether instructional, historical or educational; including questioning society; which is a thematic purpose for Dramatic narrative (Morgan \& Saxton, 1987). 


\section{Adolescent Identity}

Adolescent Identity understanding is within the domain of psychology. Mask in society and the community; have been explored by scholars in history and anthropology. It also compliments the psychology of identity. Theatrical practice is distinct from educational practice, though it informs the philosophical rationale of Drama in education and the possible impacts and resonances. Part of the role that masks have been shown to develop is the physicality of a performer and their control.

Identity and self-concept are often interchangeable terms in education, though for this writing, the term 'identity' will be used as it encompasses broader concepts than those of the "self-concept" (Berk, 2005; Harter, 2003). For adolescents the key idea of a general sense of self, along with beliefs and attitudes, is developing. This is in particularly with peer relationships (Wigfield, Byrnes, \& Eccles, 2006). It was Erik Erikson's Psychosocial Theory that emphasised the search for identity in the emergence of self through relationships with others and the role of culture (Erikson, 1963). Erikson developed a framework listing eight stages of psychosocial development (Table 1).

He placed greatest emphasis on the adolescent stage of Psychosocial Development, positing that it was the crucial stage in identity development.

For Erikson, the key factor in adolescence effecting psychological change was the impact of what the individual does rather than what is done to the individual. It is in this respect that engagement with education and learning becomes crucial. In the industrial model of education often 'learning' is 'done' to children rather than children taking control (Hattie, 2008; Robinson, 2011; Vygotsky, 1986).

Identity and Engagement are bound to each other in Education (Cooper, 2014). If we recognise that engagement is a key tool in supporting achievement and that identity development in all its forms, underlies this engagement. The importance of any pedagogical tool, such as masks, that potentially embraces both these concepts of engagement and identity, becomes apparent.

"Adolescents experience the highest levels of investment and gratification-facets of emotional engagement-in activities and relationships that positively influence their identity development." (Cooper, 2014: p.365)

It is assumed that through exploring roles in Drama, adolescent children are able to deal with who they are.

"Many teachers believe that participation in Drama In Education (DIE), where students are encouraged to take on roles of others, facilitates the development of their students socially, emotionally and intellectually.

Table 1. Erikson's eight stages of psychosocial development.

\begin{tabular}{|c|c|c|c|}
\hline & Stages & $\begin{array}{l}\text { Approximate } \\
\text { Age }\end{array}$ & Description \\
\hline 1. & Trust vs. Mistrust & 0 - 1 year & $\begin{array}{l}\text { Through having basic needs met or not, children develop a deep-seated ideal of } \\
\text { optimism or pessimism in relationships and the worlds. Core to this is the emotional } \\
\text { and trust bond formed between caregivers and the child. }\end{array}$ \\
\hline 2. & $\begin{array}{l}\text { Autonomy vs. } \\
\text { Shame and Doubt }\end{array}$ & 2 - 3 years & $\begin{array}{l}\text { Confidence is embedded here through success or failure of achievements and others reactions } \\
\text { to this. It is also through being disciplined and being offered opportunities to assert control. }\end{array}$ \\
\hline 3. & Initiative vs. Guilt & 3 - 5 years & $\begin{array}{l}\text { Through taking control and being creative and independent, a child develops a sense of self, } \\
\text { but this can also lead to clashes with those with whom the child has imprinted with } \\
\text { that can lead to guilt when in conflict. }\end{array}$ \\
\hline 4. & $\begin{array}{l}\text { Industry } \\
\text { (competence) } \\
\text { vs. Inferiority }\end{array}$ & $6-12$ years & $\begin{array}{l}\text { At this stage the basic skills sets are developed and feelings of failure and incompetence } \\
\text { are set in place. Schools have a key role in developing a self-confident child willing to } \\
\text { expand and explore. It is interesting to see the rise of standardised testing within this } \\
\text { age group and rankings, and the effect this will have on children's sense of self. }\end{array}$ \\
\hline 5. & $\begin{array}{l}\text { Identity vs. Role } \\
\text { Confusion }\end{array}$ & 13 - 18 years & $\begin{array}{l}\text { In adolescence children start to see themselves as individuals with a role to play in the } \\
\text { wider society, separate from our family. In this stage the greater impact is from } \\
\text { what children do rather than what is being done to them. }\end{array}$ \\
\hline 6. & $\begin{array}{l}\text { Intimacy vs. } \\
\text { Isolation }\end{array}$ & 18 - 40 years & Relationships and interactions with others form the core at this stage \\
\hline 7. & $\begin{array}{l}\text { Generativity vs. } \\
\text { Stagnation }\end{array}$ & $\begin{array}{l}40 \text { - } 65 \text { years } \\
\text { Adulthood }\end{array}$ & $\begin{array}{l}\text { This age looks to have purpose and meaning in what is done or be isolated } \\
\text { and adrift both physically and emotionally through lack of purpose. }\end{array}$ \\
\hline 8. & $\begin{array}{l}\text { Ego Integrity vs. } \\
\text { Despair }\end{array}$ & Old Age & $\begin{array}{l}\text { The identity is reflective, looking back at past success or failure } \\
\text { with senses of contentment or resentment at the world as a whole. }\end{array}$ \\
\hline
\end{tabular}


What is often assumed, but has been harder to substantiate, is that drama has a unique role to play in this development. Questions remain, however, as to what the nature of this contribution is, and to what degree. Evidence that would substantiate these claims would strengthen the arguments that drama be included as part of a core curriculum.” (Wright, 2006: p. 43)

Wright has explored identity and adolescents in Drama through role-play (Wright, 2006), but this feeds to the model of self-discrepancy where students can explore ideals in identity rather than reality (Higgins, 1987). Masks allow the individual to present as a self, through disguise, which supports Erikson who saw the identity of self in competition with role confusion, where children are exploring whom they are. This is in relation to gender, role, politics and religion. Drama experiences at this age stage allow children to explore these concepts and their place within them in a safe environment. If we look at the role of the mask in developing a sense of distance from the self, it allows a safe place for these explorations to be undertaken whilst potentially not imposing identities upon children. Masks allow children to look at multiple roles and take control, in part of who they are becoming (Roy \& Dock, 2014).

Erikson's model of identity sits well with the potential application of masks and drama in supporting selfdevelopment but is based upon an extension of Freud's psychosexual orientation to personality. The key development being that Erikson saw others as interacting with the self rather than as objects, thus allowing for adaptability in the environment. His analysis moved from pathology to healthy functioning. That stated it was a concept of identity grounded in a white, male, western context. Erikson's psychosocial construct of ego identity must be understood through the interaction of biological need, ego organisation and social context but it is important as a starting point for understanding the role that mask and Drama play in adolescent identity for those very same reasons.

Psychodynamic theory such as Blos's concept of individualisation lacks a strong empirical foundation (Kroger, 2004) and has a focus on infant individualisation and the severing of familial bonds. This is therefore less relevant in an education setting. Piaget and Kohlberg's concepts of identity (Cole, Engestrom, \& Vasquez, 1997) do have a greater relevance as they build and extend upon Erikson's ideas. Whilst Kohlberg implied that unlike Erikson, age may not be an accurate indicator of reason and thus self-awareness in identity; age related trends are apparent in his theories. In addition, in the Occidental Education structure on which this study is based, works upon an age based system. Piaget's relationship context for identity was based more upon the development of cognition in relation to the natural or physical world. When we put Erikson', Piaget and Kohlberg's theories and processes together we can see that they work in conjunction. Erikson's framework of identity can be explored through a cognitive-development lens.

Erikson's initial framework is key as it underpins other identity formation concepts such as Loevinger's assertion of ego as the master trait. Kegan's constructive-developmental approach (Kroger, 2004) also supports Erikson's definition of Identity vs. Role Confusion as similar to Erikson, Kegan sees events being interpreted and forming individual views and reactions to the world around us. In particular Kegan supports the theory proposed here that we should care whether or not masks have an impact on student mental health well-being and identity. He argues for a curriculum that addresses the growth of an individual mentally, not just develop a skill set.

All of the above stated models of identity formation fit the occidental society. This is a society that has been thought of as to be dysfunctional in a traditional community sense (Hewlett, 2013). It must be noted that whilst this study is approaching identity from an occidental perspective, in the multicultural world with multiple cultures and communities re-combing continually, this theoretical perspective does not sit comfortably with individuals from alternative minority groupings. Cultural contexts of identity formation must always be taken into account. Identity understandings and formations have been shown to be significantly different for minority groups. The reason for adopting such an occidental bias approach therefore, is that whilst the individuals within the educational system may have varying contexts, the actual system being studied is occidental based.

\section{Drama and Non-Academic Outcomes}

The relationship to the arts and drama with non-academic outcomes is clear, though the separation of the two, academic and non-academic, is open to question, as there has been no opportunity to isolate different factors (Cziboly, 2010; Martin et al., 2013). What is clear is that self esteem, life satisfaction and a sense of purpose and meaning as part of identity related development are supported through engagement with the arts and with drama 
(Galaska \& Krason, 2011; Rose-Krasner, Busseri, Willoughby, \& Chalmers, 2006; Shanahan \& Flaherty, 2001).

"There is a visible impact of creative activity on the development of an individual's self-creation. The ability to experience oneself as an object of creativity is the condition for a creative attitude. It is assumed that as a result of creativity and through creativity a child may enrich knowledge of themselves, gather positive experiences from their own actions which in turn enhances their positive self esteem” (Galaska \& Krason, 2011: p. 5)

Drama, as applied through a constructivism perspective, can also be used as a pedagogical tool through the self-discrepancy theory. Self-discrepancy theory is an aspect of self-concept or identity. It is an understanding of the relationship and differences among:

- How I see myself;

- How I ideally like to be;

- How I think I should be;

This is important as it recognises and validates the sense of self whilst opening up the potential for others senses of self-identity. It forces the individual to not only recognise the possibilities but if applied in the two cognitive dimensions of the theory: domains and standpoints, then the individual can explore alternatives and make informed choices. Drama is recognised through using making, as having a significant impact on an individual's self-discrepancy (Wright, 2006).

Domains of the self are the foundational basis of Self-Discrepancy Theory (actual, ideal and ought self). Standpoints or self-representations of the self are positional aspects of whom we are and others being. When we link this to the theories of mask as representing the "other" and tie this to drama pedagogies such as invisible theatre (Boal, 1998) of Boal or other role-playing techniques (Lee, Patall, Cawthon, \& Steingut, 2015), the potential for harnessing self actualisation of students in the classroom is apparent.

"The question of whether actors should work on a role from the inside (through emphatic identification with the character's psychology) or from the outside (by manifesting character through physical imitation of observable social behaviour) was rendered irrelevant in Saint-Denis's work with neutral masks. Such an inner/outer dichotomy often troubles actors who train in Strasberg's Method but spend most of their working life having to act to order as a consequence of the technical requirements of stage, television, or film. Mask was to teach the student actor an improvisational process that integrated the consciousness of aesthetic form with the experience of subjective impulse in performance. By developing a corporeal economy appropriate to expressing the personality of the mask, the student would acquire a physical discipline that prepared him for the performance of a wide range of dramatic styles.” (Gordon, 2006: p. 163)

There is strong evidence that demonstrates that drama has an impact on individuals in their wider school learning and place in society (Martin et al., 2013). Masks can be a clear methodology for allowing identity exploration, self-awareness in developing good mental health, and in conjunction with academic achievement, self-confidence and societal responsibility. There is an argument that they should be embedded into the curriculum, rather than limited those few students whose teachers have been exposed to their potential.

\section{References}

Barba, E., \& Savarese, N. (2006). A Dictionary of Theatre Anthropology (R. Fowler, Trans., 2nd ed.). New York: Routledge. Berk, L. E. (2005). Infants, Children and Adolescents (5th ed.). Boston, MA: Allyn \& Bacon.

Boal, A. (1998). Legislative Theatre. London: Routledge.

Campbell, J. (1969). The Masks of God: Primitive Mythology. New York: Penguin Compass.

Ching, E. D., \& Ching, K. (2006). Faces of Your Soul. Berkley, CA: North Atlantic Books.

Cole, M., Engestrom, Y., \& Vasquez, O. (Eds.) (1997). Mind, Culture, and Activity. Cambridge: Cambridge University Press.

Cooper, K. J. (2014). Eliciting Engagement in the High School Classroom: A Mixed-Methods Examination of Teaching Practices. American Educational Research Journal, 51, 363-402.

Cziboly, A. (Ed.) (2010). The DICE Has Been Cast: Research Findings and Recommendations on Educational Theatre and Drama. Lisbon: DICE.

Edson, G. (2005). Masks and Masking: Faces of Tradition and Belief Worldwide (Vol. Jefferson, NC). Jefferson, NC: McFarland.

Erikson, E. (1963). Childhood and Society. New York: Norton.

Foreman, J. (2000). Maskwork. Cambridge: The Lutterworth Press. 
Galaska, A., \& Krason, K. (2011). Drama Movement Techniques and Formation of Self-Creative Competences of a Child at the Early School Age-Initial Approach. Drama Research: International Journal of Drama in Education, 2.

Griffiths, D. (1998). Acting through Mask (Vol. 1). Amsterdam: Harwood Academic Publishers.

Hamilton, L. H. (1997). The Person behind the Mask. London: Ablex Publishing.

Harter, S. (2003). The Development of Self-Representation during Childhood and Adolescence. In M. R. Leary, \& J. P. Tangney (Eds.), Handbook of Self and Identity (pp. 610-642). New York: Guilford.

Hattie, J. (2008). Visible Learning. London: Routledge.

Hewlett, B. L. (Ed.) (2013). Adolescent Identity: Evolutionary, Cultural and Developmental Perspectives. New York: Routledge.

Higgins, E. T. (1987). Self-Discrepency Theory: A Theory Relating Self and Affect. Psychological Review, 94, 319-340. http://dx.doi.org/10.1037/0033-295X.94.3.319

Just, P., \& Monaghan, J. (2000). Social and Cultural Anthropology: A Very Short Introduction. London: Oxford University Press.

Kroger, J. (2004). Identity in Adolescence. London: Routledge. http://dx.doi.org/10.4324/9780203346860

Lee, B. K., Patall, E. A., Cawthon, S. W., \& Steingut, R. R. (2015). The Effects of Drama-Based pedagogy on PreK-16 Outcomes: A Meta-Analysis of Research from 1985 to 2012. Review of Educational Research, 85, 3-49. http://dx.doi.org/10.3102/0034654314540477

Lévi-Strauss, C. (1982). The Way of Masks (S. Modelski, Trans.). Seattle, WA: University of Washington Press.

Mack, J. (Ed.) (1994). Masks and the Art of Expression. New York: Abrams.

Martin, A. J., Mansour, M., Anderson, M., Gibson, R., Liem, G. A. D., \& Sudmalis, D. (2013). The Role of Arts Participation in Student's Academic and Nonacademic Outcomes: A Longitudinal Study, Home, and Community Factors. Journal of Educational Psychology, 105, 709-727. http://dx.doi.org/10.1037/a0032795

Moore, A., \& Lloyd, D. (1990). V For Vendetta. New York: Vertigo/DC Comics.

Morgan, N., \& Saxton, J. (1987). Teaching Drama: A Mind of Many Wonders. Cheltenham: Stanley Thornes.

Nunley, J. W., \& McCarthy, C. (1999). Masks: Faces of Culture. New York: Abrams.

Pollock, D. (1995). Masks and the Semiotics of Identity. The Journal of the Royal Anthropological Institute, 1, 581-597. http://dx.doi.org/10.2307/3034576

Robinson, K. (2011). Out of Our Minds: Learning to be Creative (2nd ed.). New York: Capstone.

Rose-Krasner, L., Busseri, M. A., Willoughby, T., \& Chalmers, H. (2006). Breadth and Intensity of Youth Activity Involvement as Contexts for Positive Development. Journal of Youth and Adolescence, 35, 365-379. http://dx.doi.org/10.1007/s10964-006-9037-6

Roy, D., \& Dock, C. (2014). Dyspraxia, Drama and Masks: Applying the School Curriculum as Therapy. Journal of Applied Arts and Health, 5, 369-375. http://dx.doi.org/10.1386/jaah.5.3.369 1

Shanahan, M. J., \& Flaherty, B. P. (2001). Dynamic Patterns of Time Use in Adolescence. Child Development, 72, 385-401. http://dx.doi.org/10.1111/1467-8624.00285

Twycross, M., \& Carpenter, S. (2002). Masks and Masking in Medieval and Early Tudor England. Aldershot: Ashgate.

Urban, G., \& Hendriks, J. W. (1983). Signal Functions of Masking in Amerindian Brazil. Semiotica, 47, 181-216.

Vygotsky, L. S. (1986). Thought and Learning. Cambridge, MA: The MIT Press.

Wainscott, R., \& Fletcher, K. (2010). Theatre: Collaborative Acts (3rd ed.). Boston, MA: Allyn \& Bacon.

Wigfield, W., Byrnes, J. P., \& Eccles, J. S. (2006). Development during Warly and Middle Adolescence. In P. A. Alexander, \& P. H. Winne (Eds.), Handbook of Educational Psychology (2nd ed., pp. 87-113). New York, NY: Erlbaum.

Wilsher, T. (2007). The Mask Handbook: A Practical Guide. Abingdon: Routledge.

Wright, P. (2006). Drama Education and Development of Self: Myth or Reality? Social Psychology of Education, 9, 43-65. http://dx.doi.org/10.1007/s11218-005-4791-y 